\title{
Impact of Professional Identity on Role Stress in Nursing Students in Pakistan
}

\author{
Maha Ibrahim* \\ 1-KM Defence Road, Lahore, Pakistan \\ Muhammad Afzal \\ Associate Professor, The University of Lahore, PO box 54000, Lahore, Pakistan \\ Muhammad Hussain \\ Assistant Professor, The University of Lahore, PO box 54000, Lahore, Pakistan \\ Syed Amir Gillani \\ Professor, The University of Lahore, PO box 54000, Lahore, Pakistan
}

\begin{abstract}
Introduction: Each individual has own personalized identity and role given as per their family and society, which they abide by. But as growing up and taking responsibilities, the choice an individual has to make while becoming a health care practitioner they are unaware of the transitions that will come in their way. It is clearly stated that the transition of a medical or nursing student into health care professional requires numerous changes. Among these is the advancement of an appropriate professional personality, which helps within the establishment of a sound base for proficient professional practice and so ought to be a center for medical teachers.Methods: Study was conducted in a private university. A Cross-sectional co-relational study design was used. The target population was the nursing students of a private university in Lahore. Convenient probability sampling method was used. The Role Stress Scale (score run: 12-60) and the Professional Identity Questionnaire for Nursing students (score run: 17-85) was utilized to explore the dimensions of nursing students role pressure and professional personality. Higher scores showed larger amounts of role pressure and professional identity. Fundamental statistic data about the nursing students were gathered.Results: Professional identity had significant impact of role stress in nursing studentsConclusions: This study was to assess the impact of professional identity on role stress of nursing students in Pakistan after the analysis of data it was indicated that professional identity has significant impact on role stress in nursing students.
\end{abstract}

Keywords: Professional Identity, Role Stress, Nursing Students

DOI: $10.7176 / \mathrm{JHMN} / 62-14$

Publication date:May $31^{\text {st }} 2019$

\section{Introduction}

Each individual has own personalized identity and role given as per their family and society, which they abide by. But as growing up and taking responsibilities, the choice an individual has to make while becoming a health care practitioner they are unaware of the transitions that will come in their way. It is clearly stated that the transition of a medical or nursing student into health care professional requires numerous changes. Among these is the advancement of an appropriate professional personality, which helps within the establishment of a sound base for proficient professional practice and so ought to be a center for medical teachers (Langendyk, Hegazi, Cowin, Johnson, \& Wilson, 2015)

All through the education nursing students are boarding on the way to become experts. They begin to create a sense of their individual and proficient values, convictions and concepts through their engagement with the course, the instruction and hone association, and their exchanges with faculty, staff and other students. These energetic and persistent intuitive will empower them to create and build information around their subject, their calling to others and themselves. In spite of the fact that there's no commonly acknowledged definition of professionalism or professional identity in nursing or in fact to other healthcare disciplines, these terms are both utilized to incorporate properties that are for the most part considered noteworthy in a healthcare professional, as cited that proficient character is having keenness, being patient-centered, appearing sympathy, being a great communicator, being fastidious (Bridges, 2018).

In spite of the fact that a few components of polished skill can be and are unequivocally instructed and practiced inside the undergrad educational modules, numerous angles depend upon the procurement through other implies of individual, as well as proficient, values and behaviors (Bridges, 2018).

At the point when there is an ambiguity between the apparent job desires and accomplishment, that is role conflict. Because of the distinctions found in the ability to persevere through the pressure brought about by this inconsistency, unmistakably the pressure adapting ampleness and stress response of people will vary (Akgunduz, 
2015).

While part uncertainty impacts proficient personality and work fulfillment, highlighting the requirement for clarification brings in the role ambiguity (Sayers, Salamonson, DiGiacomo, \& Davidson, 2015).

Then again the role over load where nursing proficient self-idea is that the attendants disguised qualities and convictions and the way to such an extent that they influence their considerations and conduct. The inquiries of how nursing understudies see themselves and what characteristics intrigue them are of extraordinary significance. Applying procedures that will upgrade understudies' proficient self-idea are fundamental to improving their clinical execution (Poorgholami, Ramezanli, Jahromi, and Jahromi, 2016).

Social comparison and self reflection is another strategy for picking up information, aptitudes and involvement with various societies for medical attendants and nursing understudies is through a global inundation and involvement with preparing in language, culture and network nursing (Long, 2016).

Career choice independence to individual interests help and mind alongside earlier human services exposures were found to impact the decision of the students. Occupation prospects, for example, the simplicity of finding a new line of work, work dependability, and employment compensation were considered. Nursing was seen as a course for students with poor scholastic capacity. Confusions about the idea of work and an absence of social acknowledgment were distinguished as deflecting factors in a person's decision of nursing as a profession (Liaw et al., 2016).

Social help did not fill in as a buffer against the negative impacts of over-burden on burnout. Social modeling was reasoned that endeavors to lighten burnout should straightforwardly address the degree of over-burden or the absence of help. Any endeavor to moderate the over-burden to burnout relationship by just enhancing the measure of help isn't probably going to be successful (Fong, 2016).

Retention benefits and risk of turnover is evidences by the issue that, nurse shortages have been recognized as key to workforce issues in health services frameworks internationally and in spite of the fact that mediations to expand the nursing workforce have been actualized, medical caretakers departing their jobs, especially in the main year after capability, present a huge boundary to building the nurse attendant workforce (Brook, Aitken, Webb, MacLaren, and Salmon, 2018).

Feelings of anxiety in nursing students run from moderate to high. Fundamental stressors distinguished included worry through the care of patients, assignments and tasks at hand, and negative connections with staff and personnel (Labrague et al., 2017).

Research has discovered that training pressure and adapting practices can have either a negative or positive impact on the learning and performance of nursing students (Eng and Pai, 2015).The most widely recognized adapting practices utilized were "critical thinking" and "remaining hopeful". There was a huge distinction in seen worry among understudies as to the method for picking nursing (Hamaideh, Al-Omari, and Al-Modallal, 2017).

Nursing students prevailing coping style was emotion focused adapting. Adapting and identity changes experienced by nursing students all through their degree program appear to reflect the expert skills required by future licensed nurses (Fornes-Vives, Garcia-Banda, Frias-Navarro, and Rosales-Viladrich, 2016).

\section{Literature Review}

Caring is perceived as the embodiment of nursing and the center of nursing practice while a constructive expert character can prompt individual, social and expert satisfaction. Examining minding characters and expert personality yields essential signs for the improvement (Guo, Yang, Ji, and Zhao, 2018).

As indicated by an investigation nursing students are found to have fundamentally more pressure, uneasiness, rest aggravations, and stress-related sicknesses than the general student body. Nurses reliably report the most abnormal amounts of occupation worry among all health care experts. To best get ready understudies for such a high-stress calling, bits of knowledge into the beginning of pressure is justified, particularly with the writing supporting that nursing understudy's experience huge worry amid their instruction (Bartlett, Taylor, and Nelson, 2016).

Graduate nursing students proficient personality was not palatable and one procedure to improve this is to disguise minding into the instruction procedure. Nursing instructors should concentrate more on the arrangement of the student's proficient personality and minding as a contributing component to it (Guo et al., 2018)

The discoveries feature the significance of self-care and stress the board abilities training in attendant preliminary projects for use in both scholastic readiness and in future professions (Bartlett et al., 2016).

According to an investigation comprehensively, more consideration could be given to the potential job of versatility preparing and different structures successful adapting methodologies to manage the unavoidable wellsprings of worry in understudy nurture preparing (Smith and Yang, 2017).

In contrast with it another examination upheld the idea of a feeling of having a place as a crucial human need, having a positive impact and effect on understudies' learning, inspiration and certainty. Conversely, saw pressure has negative outcomes on the understudies' self-idea, learning aptitudes and capability (Grobecker, 2016).

The consequences of another investigation demonstrated that amid clinical practice, assignments and 
remaining burden was the most widely recognized worry to understudies; transference was the most habitually utilized adapting technique by understudies. Self-efficacy not just had a positive principle impact in foreseeing the recurrence of utilization of remaining hopeful and critical thinking systems yet in addition directed the impacts of worry from dealing with patients on transference procedure, just as worry from assignments and outstanding task at hand on critical thinking methodology (Zhao, Lei, He, Gu, and Li, 2015).

A solid contention leaves that medicinal and nursing teachers plan to ingrain in their understudies solid word related characters which may sustain progressive disciplinary limits. In this manner, it is proposed that wellbeing callings instructors should move past current disciplinary storehouses and make between expert training open doors for therapeutic understudies and nursing understudies to adapt together to encourage the advancement of the synergistic between expert characters essential for the conveyance of fantastic, persistent focused social insurance (Langendyk et al., 2015).

Various research contemplates reasons that proficient socialization in nursing is profoundly hazardous in light of the fact that newcomers begin relating to the calling's standards however lose this vision as they enter and keep on working in the calling (Traynor and Buus, 2016).

Understudies ordinarily underscored their expert way of life as the reason for duty, albeit numerous members likewise featured an absence of acknowledgment by qualified professionals, which diminished it. There was proof that proposed that expert remaining task at hand may affect the understudy understanding because of difficulties in setting aside a few minutes to offer help (Clements, Kinman, Leggetter, Teoh, and Guppy, 2016).

Attendant Match instrument endeavors to guarantee just the applicants with the "right" individual personalities and qualities comparable with the Professional Identity of Nursing (PIN) are acknowledged for medical caretaker instruction: Nurse Match offers advancement to help this (Mazhindu et al., 2016).

Graduate nursing understudies apparent they had positive minding characters while their expert personality was at a low dimension. A noteworthy positive relationship was found between the Nursing Caring Characters Assessment Tool and Professional Identity Scale for Nursing Students (Guo et al., 2018).

\section{Methodology}

Study will be conducted in the private university of Lahore. A Cross-sectional co-relational study design will be used. The target population will be the nursing students of a private university in Lahore. Convenient probability sampling method was used. The Role Stress Scale (score run: 12-60) and the Professional Identity Questionnaire for Nursing students (score run: 17-85) will be utilized to explore the dimensions of nursing students role pressure and professional personality. Higher scores showed larger amounts of role pressure and professional identity. Fundamental statistic data about the nursing students will be gathered.

\section{Results}

This chapter consists of 3 parts, to investigate the impact of professional identity on role stress from the data collected from the participants. The demographic data of the study includes detail information regarding the participant's gender, program enrolled, marital status, only child, place of residence, part time work experience, experience in community organization and reason for enrollment in nursing which is given in the table below. Moreover, co-relation, normality rest and point bi-serial analysis has been performed. 


\begin{tabular}{|c|c|c|c|c|c|c|}
\hline $\begin{array}{l}\text { S. } \\
\text { No }\end{array}$ & Variables & & Mean & S.D & Number & $\%$ \\
\hline \multirow[t]{2}{*}{1} & Gender & Male & \multirow[t]{2}{*}{1.90} & \multirow[t]{2}{*}{.298} & 10 & 9.7 \\
\hline & & Female & & & 93 & 90.3 \\
\hline \multirow[t]{2}{*}{2} & Program Enrolled & $\begin{array}{l}\text { Bachelors of Science in Nursing } \\
\text { (Hons) }\end{array}$ & \multirow[t]{2}{*}{1.39} & \multirow[t]{2}{*}{.490} & 63 & 61.2 \\
\hline & & $\begin{array}{l}\text { Bachelors of Science in Nursing } \\
\text { (Post RN) }\end{array}$ & & & 40 & 38.8 \\
\hline \multirow[t]{2}{*}{3} & Marital Status & Married & \multirow[t]{2}{*}{1.88} & \multirow[t]{2}{*}{.322} & 12 & 11.7 \\
\hline & & Un- married & & & 91 & 88.3 \\
\hline \multirow[t]{2}{*}{4} & Only Child & Yes & \multirow[t]{2}{*}{1.93} & \multirow[t]{2}{*}{.253} & 7 & 6.8 \\
\hline & & No & & & 96 & 93.2 \\
\hline \multirow[t]{2}{*}{5} & Place of Residence & Urban & \multirow[t]{2}{*}{1.02} & \multirow[t]{2}{*}{.139} & 101 & 98.1 \\
\hline & & Countryside & & & 1.9 & 2 \\
\hline \multirow[t]{2}{*}{6} & Part time work experience & Yes & \multirow[t]{2}{*}{1.76} & \multirow[t]{2}{*}{.431} & 25 & 24.3 \\
\hline & & No & & & 78 & 75.7 \\
\hline \multirow[t]{2}{*}{7} & $\begin{array}{l}\text { Experience in Community } \\
\text { Organization }\end{array}$ & Yes & \multirow[t]{2}{*}{1.60} & \multirow[t]{2}{*}{.492} & 41 & 39.8 \\
\hline & & No & & & 62 & 6.2 \\
\hline \multirow[t]{3}{*}{8} & $\begin{array}{l}\text { Reason for Enrollment in } \\
\text { Nursing }\end{array}$ & Personal Interests & \multirow[t]{3}{*}{2.16} & \multirow[t]{3}{*}{.683} & 17 & 16.5 \\
\hline & & Recommendations of teachers & & & 53 & 51.5 \\
\hline & & $\begin{array}{lll}\begin{array}{l}\text { Recommendations of } \\
\text { Members }\end{array} & \text { Family } \\
\end{array}$ & & & 33 & 32 \\
\hline
\end{tabular}

Participants included in the study 9.7\% (10) were male and 90.3\% (93) were female. Table.2 shows that $90.3 \%$ (93) participants were female, whereas 9.7\% (10) were male, ratio of male to female nurses in low as the majority of nurses in Pakistan are female. The program enrolled in response of participants showing that $61.2 \%(63)$ participants were from Bachelors of Science in Nursing (Hons) and 38.8\% (40) participants were from 61.2\% (63). The marital status related response was that the $11.7 \%$ (12) participants were married and $88.3 \%$ (91) participants were un-married. $6.8 \%$ (7) participants were the only child where as $93.2 \%$ (96) participants were not the only child. In response to the place of residence $98.1 \%(101)$ participants were from urban areas and $1.9 \%(2)$ participants were from the countryside. $39.8 \%(41)$ participants had previous community organization experience whereas $60.2 \%(62)$ participants had no previous community organization experience. $16.5 \%(17)$ participants enrolled in nurse due to personal interests, 51.5\%(53) participants enrolled on the recommendations of teachers and $32 \%(33)$ participants had enrolled on the recommendations of family members.

Table 2: Correlation between subscales of Professional Identity Questionnaire Nursing Students (PIQNS) and Role Stress Scale (RSS) among Nurses among Nursing Students

\begin{tabular}{|c|c|c|c|c|}
\hline & \multicolumn{2}{|c|}{ Subscales of Role Stress Scale } & \\
\hline $\begin{array}{c}\text { Subscales of Professional Identity Nursing } \\
\text { Students Questionnaire }\end{array}$ & $\begin{array}{c}\text { Role } \\
\text { Conflict }\end{array}$ & $\begin{array}{c}\text { Role } \\
\text { Overload }\end{array}$ & $\begin{array}{c}\text { Role } \\
\text { Ambiguity }\end{array}$ & Total \\
\hline Professional Self Image & $\mathrm{r}=-0.98$ & $\mathrm{r}=-0.974$ & $\mathrm{r}=-0.981$ & \\
& $\mathrm{p}=0.001$ & $\mathrm{p}=0.001$ & $\mathrm{p}=0.001$ & \\
\hline Retention benefit and risk of turnover & $\mathrm{r}=-0.974$ & $\mathrm{r}=-0.968$ & $\mathrm{r}=-0.974$ & \\
& $\mathrm{p}=0.001$ & $\mathrm{p}=0.001$ & $\mathrm{p}=0.001$ & \\
\hline Social comparison and self-reflection & $\mathrm{r}=-0.98$ & $\mathrm{r}=-0.974$ & $\mathrm{r}=-0.981$ & \\
& $\mathrm{p}=0.001$ & $\mathrm{p}=0.001$ & $\mathrm{p}=0.001$ & \\
\hline Career choice independence & $\mathrm{r}=-0.985$ & $\mathrm{r}=-0.979$ & $\mathrm{r}=-0.987$ & \\
& $\mathrm{p}=0.001$ & $\mathrm{p}=0.001$ & $\mathrm{p}=0.001$ & \\
\hline Social modelling & $\mathrm{r}=-0.975$ & $\mathrm{r}=-0.969$ & $\mathrm{r}=-0.975$ & \\
& $\mathrm{p}=0.001$ & $\mathrm{p}=0.001$ & $\mathrm{p}=0.001$ & $\mathrm{r}$ \\
\hline Total & & & & 0.985 \\
& & & & $\mathrm{p}=0.001$ \\
\hline
\end{tabular}

Table 2 represents the impact of professional identify on role stress. The relationship was significant, as the $\mathrm{p}$ value were less than 0.005 . 
Table 3: Point-biserial correlation coefficient Between Role Stress and Demographics of the participants

\begin{tabular}{|c|c|c|c|}
\hline Variables & \multicolumn{3}{|c|}{ Subscales of Role Stress Scale } \\
\hline & Role Conflict & Role Overload & Role Ambiguity \\
\hline Age & $\mathrm{r}=0.63$ & $\mathrm{r}=-0.63$ & $\mathrm{r}=-0.654$ \\
& $\mathrm{p}=0.001$ & $\mathrm{p}=0.001$ & $\mathrm{p}=0.001$ \\
\hline Marital Status & $\mathrm{r}=0.33$ & $\mathrm{r}=-0.33$ & $\mathrm{r}=-0.33$ \\
& $\mathrm{p}=0.001$ & $\mathrm{p}=0.001$ & $\mathrm{p}=0.001$ \\
\hline Gender & $\mathrm{r}=0.44$ & $\mathrm{r}=-0.442$ & $\mathrm{r}=-0.445$ \\
& $\mathrm{p}=0.001$ & $\mathrm{p}=0.001$ & $\mathrm{p}=0.001$ \\
\hline Place of Residence & $\mathrm{r}=00191$ & $\mathrm{r}=-0.192$ & $\mathrm{r}=-0.191$ \\
& $\mathrm{p}=0.05$ & $\mathrm{p}=0.05$ & $\mathrm{p}=0.05$ \\
\hline Educational Level & $\mathrm{r}=-0.700$ & $\mathrm{r}=-0.6$ & $\mathrm{r}=-0.719$ \\
& $\mathrm{p}=0.001$ & $\mathrm{p}=0.001$ & $\mathrm{p}=0.001$ \\
\hline Part Time Work Experience & $\mathrm{r}=-0.35$ & $\mathrm{r}=-0.322$ & $\mathrm{p}=0.397$ \\
& $\mathrm{p}=0.001$ & $\mathrm{p}=0.001$ & $\mathrm{r}=-0.001$ \\
\hline Experience in Community & $\mathrm{r}=-0.701$ & $\mathrm{p}=0.001$ & $\mathrm{p}=0.001$ \\
\hline Reason for enrollment in Nursing & $\mathrm{p}=0.001$ & $\mathrm{r}=-0.0 .287$ & $\mathrm{r}=-0.292$ \\
& $\mathrm{p}=0.001$ & $\mathrm{p}=0.001$ & $\mathrm{p}=0.001$ \\
\hline
\end{tabular}

Table. 3 shows the point biserial correlation coefficient between the role stress sub scales and demographic data of the participants. The relationship was significant, as the $\mathrm{p}$ value were less than 0.005 .

\section{Discussion}

The nursing students commonly experience role stress is understandable from a sociological perspective because they are novices and unfamiliar with the job. The findings of this study revealed that nursing students' levels of role stress were high. Their mean scores of role conflict dimension were similar to those of young nurses. However, the students in our study had higher mean scores of role ambiguity dimension than did young nurses assessed previously (Liu et al., 2013).

This study showed statistically negative correlations between nursing students' professional identity and role stress. Our results indicated that the nursing students with higher professional identity values had lower role stress levels. Compared with other personal characteristics, professional identity had the strongest impact on the nursing students' level of role stress. Additionally, education level, whether being the only child or not and whether having experience in community organisations or not also contributed, although differently, to role stress.

\section{Limitation}

Limitation of this study was shortage of time and too much less sample size 103 due to which we cannot generalize this study on whole population.

\section{Conclusion}

This study is to assess the impact of professional identity on role stress of nursing students in Pakistan after the analysis of data it was indicated that professional identity has significant impact on role stress in nursing students.

\section{ACKNOWLEDGEMENT}

I would like to thank the following people who in many ways contributed to this piece of work. First and foremost would like to thank Mr. Muhammad Afzal (The Principal of Lahore School of Nursing) who allowed me to do this study and guided me. I would thank my preceptor and the participants for the patience.

\section{References}

Akgunduz, Y. (2015). The influence of self-esteem and role stress on job performance in hotel businesses. International Journal of Contemporary Hospitality Management, 27(6), 1082-1099.

Bartlett, M. L., Taylor, H., \& Nelson, J. D. (2016). Comparison of mental health characteristics and stress between baccalaureate nursing students and non-nursing students. Journal of Nursing Education, 55(2), 87-90.

Bridges, S. J. (2018). Professional identity development: Learning and journeying together. Research in Social and Administrative Pharmacy, 14(3), 290-294.

Brook, J., Aitken, L., Webb, R., MacLaren, J., \& Salmon, D. (2018). Characteristics of successful interventions to reduce turnover and increase retention of early career nurses: a systematic review. International journal of nursing studies.

Clements, A. J., Kinman, G., Leggetter, S., Teoh, K., \& Guppy, A. (2016). Exploring commitment, professional 
identity, and support for student nurses. Nurse Education in Practice, 16(1), 20-26.

Cruess, R. L., Cruess, S. R., \& Steinert, Y. (2016). Amending Miller's pyramid to include professional identity formation. Academic Medicine, 91(2), 180-185.

Duchscher, J. E. B. (2009). Transition shock: The initial stage of role adaptation for newly graduated registered nurses. Journal of advanced nursing, 65(5), 1103-1113.

Eng, C.-J., \& Pai, H.-C. (2015). Determinants of nursing competence of nursing students in Taiwan: The role of self-reflection and insight. Nurse Education Today, 35(3), 450-455.

Fong, C. M. (2016). Role overload, social support, and burnout among nursing educators. Journal of Nursing Education, 29(3), 102-108.

Fornes-Vives, J., Garcia-Banda, G., Frias-Navarro, D., \& Rosales-Viladrich, G. (2016). Coping, stress, and personality in Spanish nursing students: A longitudinal study. Nurse Education Today, 36, 318-323.

Grobecker, P. A. (2016). A sense of belonging and perceived stress among baccalaureate nursing students in clinical placements. Nurse Education Today, 36, 178-183.

Guo, Y.-j., Yang, L., Ji, H.-X., \& Zhao, Q. (2018). Caring characters and professional identity among graduate nursing students in China-A cross sectional study. Nurse Education Today, 65, 150-155.

Hamaideh, S. H., Al-Omari, H., \& Al-Modallal, H. (2017). Nursing students' perceived stress and coping behaviors in clinical training in Saudi Arabia. Journal of Mental Health, 26(3), 197-203.

Labrague, L. J., McEnroe-Petitte, D. M., Gloe, D., Thomas, L., Papathanasiou, I. V., \& Tsaras, K. (2017). A literature review on stress and coping strategies in nursing students. Journal of Mental Health, 26(5), 471480.

Langendyk, V., Hegazi, I., Cowin, L., Johnson, M., \& Wilson, I. (2015). Imagining alternative professional identities: Reconfiguring professional boundaries between nursing students and medical students. Academic Medicine, 90(6), 732-737.

Liaw, S. Y., Wu, L. T., Holroyd, E., Wang, W., Lopez, V., Lim, S., \& Chow, Y. (2016). Why not nursing? Factors influencing healthcare career choice among Singaporean students. International nursing review, 63(4), 530538.

Long, T. (2016). INFLUENCE OF INTERNATIONAL SERVICE LEARNING ON NURSING STUDENTS'SELF EFFICACY TOWARDS CULTURAL COMPETENCE. Journal of Cultural Diversity, 23(1).

Liu, Y., Yang, M., Chen, F.F., 2013. Impact of young ICU nurses' role conflict, role ambiguity and job on their turnover intention in ICU department. Chin. J. Nurs. 48 (6), 533-535

Mazhindu, D. M., Griffiths, L., Pook, C., Erskine, A., Ellis, R., \& Smith, F. (2016). The nurse match instrument: exploring professional nursing identity and professional nursing values for future nurse recruitment. Nurse Education in Practice, 18, 36-45.

Nordin, R., \& Fredin, J. (2015). Organizational role stress: a case study in the Swedish public sector.

Poorgholami, F., Ramezanli, S., Jahromi, M. K., \& Jahromi, Z. B. (2016). Nursing students' clinical performance and professional self-concept. Bangladesh Journal of Medical Science, 15(1), 57-61.

Sayers, J., Salamonson, Y., DiGiacomo, M., \& Davidson, P. M. (2015). Nurse educators in Australia: High job satisfaction despite role ambiguity. Journal of Nurse Education and Practice.

Smith, G. D., \& Yang, F. (2017). Stress, resilience and psychological well-being in Chinese undergraduate nursing students. Nurse Education Today, 49, 90-95.

Traynor, M., \& Buus, N. (2016). Professional identity in nursing: UK students' explanations for poor standards of care. Social Science \& Medicine, 166, 186-194.

Zhao, F. F., Lei, X. L., He, W., Gu, Y. H., \& Li, D. W. (2015). The study of perceived stress, coping strategy and self-efficacy of $\mathrm{C}$ hinese undergraduate nursing students in clinical practice. International journal of nursing practice, 21(4), 401-409.

Retrieved from http://www.nln.org/docs/default-source/default-document-library/professional-identityfinal.pdf?sfvrsn=0 